\title{
Simulating the potential of trees to reduce particulate matter pollution in urban areas throughout the year
}

\author{
Chiara Letter $^{1} \cdot$ Georg Jäger $^{1}$ (D)
}

Received: 22 November 2018 / Accepted: 23 May 2019 / Published online: 28 May 2019

(C) The Author(s) 2019

\begin{abstract}
Particulate matter pollution, especially in an urban environment, is a health risk that affects many people, and the current trend shows that these problems will increase in the near future. To combat this form of air pollution, many different strategies and policies are investigated: from reducing the emission of particulate matter to finding ways of filtering the air. In this study, we explore the idea of using trees in an urban area to reduce particulate matter concentration. Since the absorption of fine dust by trees is a complex problem, influenced by many factors, we use a computer model to simulate the effect of various trees throughout the year to find the optimal candidate. We find that coniferous trees have a significant advantage, since they also absorb during the winter months, where the air quality is worse. We also conclude that a large enough area of a well-suited tree species is a feasible way to increase air quality and in some cases even to reduce the particulate matter pollution to an acceptable level.
\end{abstract}

Keywords Particulate matter $\cdot$ Pollution absorption $\cdot$ Urban pollution $\cdot$ Molecular dynamics $\cdot$ Fine dust

\section{Introduction}

Due to the continuing urbanization more and more people live in an urban environment (Castells 2010; Clark 2004; Brenner 2013). This increase in density as well as area leads to diverse challenges and problems (Zhang 2016; Simon 2007). Many of them are connected to pollution, for example noise pollution, but also air pollution in the form of many different contaminants (Tarr 1996; Taebi and Droste 2004). While the effects of $\mathrm{CO} 2$ emissions are more global and on a larger timescale, other pollutants have a more acute effect on human health and well-being. For many cities, particulate matter (PM), i.e., microscopic solid or liquid matter suspended in the atmosphere, is a significant problem. Due to their small size, the particles can enter the bloodstream via the

Georg Jäger

georg.jaeger@uni-graz.at

Chiara Letter

chiara.letter@edu.uni-graz.at

1 University of Graz, Graz, Austria 
lungs unfiltered, causing various medical conditions (Seaton et al. 1995; Harrison and Yin 2000; Thurston et al. 2005; Valavanidis et al. 2008; Lippmann et al. 2003; Anderson et al. 2012). Both WHO and IARC classify PM as a group 1 carcinogen, highlighting their potential to cause or facilitate cancer. Detailed investigations about the main sources of pollution and their effect on human health were conducted by Karagulian et al. (2015) and Belis et al. (2013).

Because of this negative effect of PM on human health, many countries implemented laws and policies to regulate the pollution. In the European Union, for example, the European emission standards also regulate particulate emissions. There are also standards for the allowed concentration of PM in the air and a limit on how often per year this limit can be exceeded. For PM10, this limit is $50 \mu \mathrm{g} / \mathrm{m}^{3}$ in an averaging period of $24 \mathrm{~h}$, which is permitted to be exceeded 35 times each year.

In order to abide by this law, two different approaches are possible. One could try to minimize the emission of PM or maximize the absorption. For minimizing emissions, different paths are explored: One could reduce emissions caused by traffic, by limiting the allowed maximal speed in areas affected by PM pollution or using dust suppressants (Baldasano et al. 2010; Amato et al. 2010). Also the industry can be forced to reduce their activities in order to limit PM emissions or to use more sophisticated filtering techniques. Such measures are effective, but they are difficult to implement, since they often lead to resistance in the population. The strategy of maximizing PM absorption on the other hand faces different challenges. While the population is generally in favor of policies that reduce air pollution without any bans or restrictions, they often require some form of investment and take longer to take effect.

One idea to change the urban landscape to increase PM absorption is planting trees in existing or newly designated green areas (Beckett et al. 1998; McDonald et al. 2007). Although absorbing PM can have a negative impact on tree growth (Rai 2016), they bind the PM permanently, leading to better conditions for surrounding vegetation. In addition to absorbing PM, trees offer other benefits as well: They absorb $\mathrm{CO} 2$ from the atmosphere to mitigate climate change and offer shade, which helps in adapting to globally rising temperatures. The main challenge for this endeavor is to select the optimal tree for filtering PM from the air. The absorption rate is not only dependent on the tree species, but also on external conditions like wind, temperature and current PM concentration (Freer-Smith et al. 2004; Kappis and Endlicher 2007). This leads to an interesting phenomenon: The tree species that absorbs most PM in the course of a year might not be the best choice to reduce the days on which the PM10 concentration is over the limit. Since the PM concentration follows a distinct pattern through the seasons (for example, in many cities the PM concentration is much higher during seasons where heating is required) and also weather and average wind speed change over the course of a year, this leads to a complex system and the optimal candidate cannot be identified without further investigation.

One promising approach to finding the species of tree best suited to reach the goal of reducing PM pollution is to use a computer simulation. For this system, the microscale is especially interesting: The interaction between leaves, the fine dust particles and the wind needs to be modeled in great detail, in order to gain accurate results. For this reason, we designed a molecular dynamics model using NetLogo (Wilensky 1999), calibrated using empirical data about the ability of different types of trees to absorb PM. Using this model, we then simulate for 1 year, which is representative in terms of PM concentration and average wind speed for each respective month, and extrapolate from the microscale to the macroscale. We then compare the effect of different types of trees and investigate what area would be needed for a significant reduction in days which exceed the PM limit. 
This paper is organized as follows: Sect. 2.1 describes the used model; the calibration of the model to empirical data is detailed in Sect. 2.2. Section 3 presents the obtained results and a sensitivity analysis of the model. Section 4 closes with a discussion and conclusions.

\section{Methods}

In order to gain new knowledge about the ability of trees to absorb PM under different circumstances, we use a molecular dynamics model (Hoover 1986). We model the microscale, i.e., the interaction between individual fine dust particles and the surface of the leaf. In that way, all relevant effects, like wind speed and PM concentration, can be included in a convenient way. Once we know the absorption rate of a single leaf, we can then extrapolate to the macroscale via the overall leaf surface of the tree. Since the empirical data we use to calibrate the model have a macroscopic perspective, the average absorption is independent of the leaf position within the model and its effect included via averages.

\subsection{Model}

The core of the model is an idealized leaf with the ability to absorb PM. It is surrounded by air, which has a certain concentration of PM. The movement of PM is governed by temperature-dependent Brownian motion ( $\mathrm{Li}$ et al. 2010) on the one hand and the wind speed on the other hand. The particles are modeled as ideal gas, so there are no collisions between gas particles. Every time a PM particle hits the surface of the leaf, there is a certain chance for the particle to be absorbed. Absorbed particles are removed from the simulation. In order for the PM concentration to remain constant, a new particle is generated at a random position. If the collision between leaf and particle does not lead to an absorption, the particle bounces off the leaf and could be absorbed at a later time. Figure 1 shows a screenshot of the running model.

Another important effect is the interaction between leaf and wind. This is different for deciduous trees and conifers. While the leaves of deciduous trees are flexible and move in the wind, so that the wind is mostly parallel to the leaf surface at higher wind speeds, the needles (here also referred to a leaves in a more general sense) show on average no preferred angle between leaf surface and wind direction. In the model, this is implemented as

Fig. 1 Screenshot of the running model: The idealized leaf (green) is surrounded by moving fine dust particles (gray)

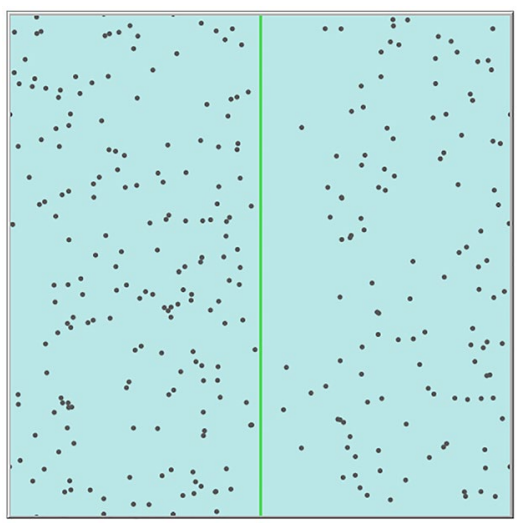

leaf surface - particulate matter 
follows: For conifers, the wind direction is completely random, while for deciduous trees only certain angles are allowed. If the wind speed exceeds $1 \mathrm{~m} / \mathrm{s}$, the angle between leaf surface and wind direction is maximally 10 degrees.

The model then simulates a certain time frame in adjustable environmental conditions and counts the number of absorbed particles. For each month, different weather and pollution conditions are chosen, so that we gain an accurate depiction of the absorption rate of different trees over the course of a year.

\subsection{Model calibration}

In order to gain realistic results, the calibration of the model to empirical data is paramount. First of all, we need to find the absorption probability of a particle hitting a leaf. Therefore, we used empirical data obtained by (Terzaghi et al. 2013), which analyzed the PM absorption capacity of trees. We used the same environmental parameters as in this study and varied the model parameter that governs the absorption probability of the leaf until the absorption capacities matched. Depending on the species, this leads to absorption probabilities between $1.7 \%$ and $3.4 \%$.

In order to find realistic parameters for weather conditions and PM pollution, we need to select a city with high PM pollution. We chose the Austrian City of Graz, a city with roughly 300000 inhabitants. Due to the city position in the basin, there is little wind and the PM concentration is very high, especially in the winter months. In the year 2017, Graz had 54 days with PM concentration above the threshold (Steiermark 2018), so significantly above the EU limit. For the calibration, we also need the weather data (average temperature and wind speed for each month) and the PM concentration for each month.

With this information we were able to simulate the absorption capacity of various trees throughout the year. We chose to investigate three species of trees that grow naturally in this area and that were investigated in (Terzaghi et al. 2013): two deciduous trees, the sycamore maple (Acer pseudoplatanus) and the Cornelian cherry (Cornus mas), and one conifer, the stone pine (Pinus pinea). These three were chosen to maximize the different types of foliage: large leaves, small leaves and needles.

\section{Results}

We perform simulations for every species of tree for each month of the year. Simulated absorption is then extrapolated and normalized to $1 \mathrm{~km}^{2}$ of green area using the leaf area index (LAI) (Iio et al. 2014). The final results are presented in Fig. 2.

It is clearly visible that the matching between pollution and absorption is very different for each species of tree. Although a high PM concentration leads to more absorption, other effects like wind speed and the loss of leaves outside the vegetation period have a significant effect. The best result was obtained for the stone pine: Since it keeps its needles during the winter, it has a high absorption potential throughout the year. Needles are also less affected by wind, so they can bind PM independent of the weather. Especially during the winter, they have a huge potential to reduce PM pollution, mainly because there is a high PM concentration. So even though all trees are suitable to absorb PM, the coniferous stone pine is the best candidate to reduce the pollution at exactly those times, where fine dust absorption is needed. 


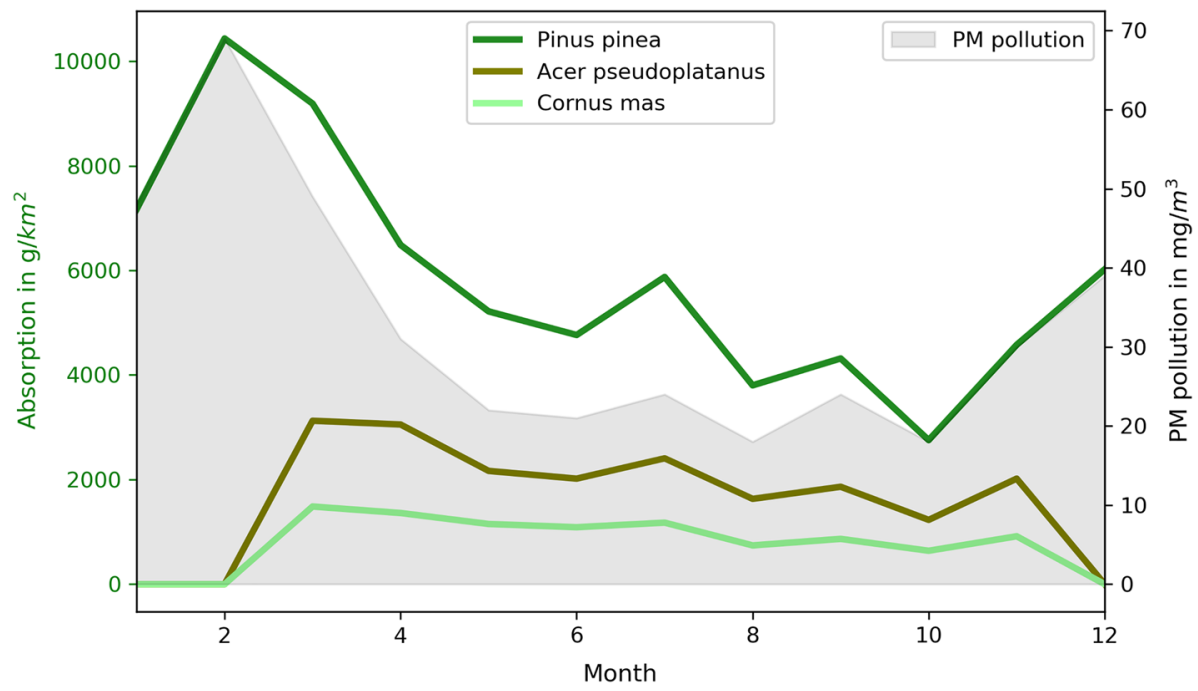

Fig. 2 Absolute PM absorption for different species of tree through the course of 1 year. While the absorption chance is constant over the year for each type of tree, differences in PM concentration, wind and foliage over the year lead to more collisions between particles and leaf surface and thus more absolute absorption. The gray background shows the average PM pollution each month

In order to see the actual effect of introducing more stone pines to the city, we need to look at the number of days where the limit was exceeded in each month, the PM emissions in that month and the added PM absorption. All the days where the PM limit was exceeded are given in Table 1 .

To gain insight into the emission of PM, we consulted (Heiden et al. 2008) to find out that during 1 year, traffic causes $154.2 \mathrm{t}$ of PM, the industry is responsible for $85.72 \mathrm{t}$ and heating (domestic and commercial) produces $72.05 \mathrm{t}$ of PM each year. Assuming that the pollution from traffic and industry is more or less constant during a year and heating is only relevant in the winter months, we find average emissions of $44.01 \mathrm{t}$ each winter month and $20.00 \mathrm{t}$ during non-winter months. This value can then be compared to the mass of PM $1 \mathrm{~km}^{2}$ of stone pines can absorb. The relative reduction in PM is given in Table 2.

Under the assumption that absorbing $\mathrm{x} \%$ of the emitted PM also reduces the PM concentration in the air by $\mathrm{x} \%$, we can then calculate the reduced PM concentrations and find out at which days the PM concentration would have been reduced to a value under the PM limit. The result of this investigation is presented in Table 3, where those days are italicized.

We see that in many cases, the PM concentration was reduced enough to be under the limit. Without the trees, there were 54 days with too much PM pollution (so significantly more than the allowed maximum of 35). With the trees, this number has been reduced by 25 to only 29 days with too much PM pollution. This value is now under the maximally allowed number, so $1 \mathrm{~km}^{2}$ of stone pines would be enough to reduce the fine dust pollution sufficiently. To gain an understanding of the size of such a forest compared to the size of the investigated city, Fig. 3 shows a map of the city (Contributors 2012), with an area of $1 \mathrm{~km}^{2}$ highlighted in green. While this is of course a large area, it is at least feasible if one would separate it into many small areas, which would also increase the absorption potential. 
Table 1 PM 10 concentration in $\mu \mathrm{g} / \mathrm{m}^{3}$ on days exceeding the limit

\begin{tabular}{lcllll}
\hline Date & PM conc. & Date & PM conc. & Date & PM conc. \\
\hline 01.01 .2017 & 157 & 30.01 .2017 & 82 & 02.11 .2017 & 53 \\
02.01 .2017 & 89 & 31.01 .2017 & 101 & 15.11 .2017 & 52 \\
03.01 .2017 & 72 & 01.02 .2017 & 114 & 17.11 .2017 & 51 \\
04.01 .2017 & 60 & 02.02 .2017 & 95 & 21.11 .2017 & 58 \\
11.01 .2017 & 82 & 09.02 .2017 & 62 & 22.11 .2017 & 67 \\
12.01 .2017 & 96 & 10.02 .2017 & 58 & 23.11 .2017 & 61 \\
17.01 .2017 & 52 & 11.02 .2017 & 61 & 24.11 .2017 & 62 \\
18.01 .2017 & 78 & 12.02 .2017 & 71 & 28.11 .2017 & 54 \\
19.01 .2017 & 78 & 13.02 .2017 & 65 & 04.12 .2017 & 76 \\
20.01 .2017 & 86 & 14.02 .2017 & 54 & 05.12 .2017 & 66 \\
21.01 .2017 & 94 & 15.02 .2017 & 58 & 07.12 .2017 & 72 \\
22.01 .2017 & 105 & 16.02 .2017 & 57 & 19.12 .2017 & 59 \\
23.01 .2017 & 140 & 17.02 .2017 & 64 & 20.12 .2017 & 52 \\
24.01 .2017 & 113 & 21.02 .2017 & 72 & 21.12 .2017 & 64 \\
25.01 .2017 & 57 & 22.02 .2017 & 51 & 22.12 .2017 & 57 \\
27.01 .2017 & 68 & 23.02 .2017 & 52 & 24.12 .2017 & 53 \\
28.01 .2017 & 71 & 22.08 .2017 & 71 & 26.12 .2017 & 51 \\
29.01 .2017 & 86 & 20.10 .2017 & 58 & 31.12 .2017 & 53 \\
\hline
\end{tabular}

Table 2 PM emission and absorption in tonnes for each month

\begin{tabular}{llcl}
\hline Month & PM emission & PM absorption & $\begin{array}{l}\text { Relative } \\
\text { change } \\
(\%)\end{array}$ \\
\hline January & 44.01 & 7.17 & 16.3 \\
February & 44.01 & 10.43 & 22.7 \\
March & 20.00 & 9.19 & 46.0 \\
April & 20.00 & 6.49 & 32.5 \\
May & 20.00 & 5.22 & 26.1 \\
June & 20.00 & 4.76 & 23.8 \\
July & 20.00 & 5.87 & 29.4 \\
August & 20.00 & 3.80 & 19.0 \\
September & 20.00 & 4.32 & 21.6 \\
October & 20.00 & 2.75 & 13.8 \\
November & 20.00 & 4.58 & 22.9 \\
December & 44.01 & 6.02 & 13.7 \\
\hline
\end{tabular}

\subsection{Sensitivity analysis}

In order to gain more insight into the accuracy of our model we performed a sensitivity analysis. We investigated the influence of the wind speed as well as the influence of PM concentration on our results. Wind speed was analyzed from $0.5 \mathrm{~m} / \mathrm{s}$ to $3 \mathrm{~m} / \mathrm{s}$ with a constant PM concentration of $50 \mu \mathrm{g} / \mathrm{m}^{3}$, while PM concentration was analyzed from $25 \mu \mathrm{g} / \mathrm{m}^{3}$ 
Table 3 PM concentration in $\mu \mathrm{g} / \mathrm{m}^{3}$ from Table 1 after absorption

\begin{tabular}{lcllll}
\hline Date & PM conc. & Date & PM conc. & Date & PM conc. \\
\hline 01.01 .2017 & 131 & 30.01 .2017 & 69 & 02.11 .2017 & 41 \\
02.01 .2017 & 74 & 31.01 .2017 & 85 & 15.11 .2017 & 40 \\
03.01 .2017 & 60 & 01.02 .2017 & 88 & 17.11 .2017 & 39 \\
04.01 .2017 & 50 & 02.02 .2017 & 73 & 21.11 .2017 & 48 \\
11.01 .2017 & 69 & 09.02 .2017 & 48 & 22.11 .2017 & 51 \\
12.01 .2017 & 80 & 10.02 .2017 & 44 & 23.11 .2017 & 47 \\
17.01 .2017 & 44 & 11.02 .2017 & 47 & 24.11 .2017 & 48 \\
18.01 .2017 & 65 & 12.02 .2017 & 55 & 28.11 .2017 & 42 \\
19.01 .2017 & 65 & 13.02 .2017 & 50 & 04.12 .2017 & 66 \\
20.01 .2017 & 72 & 14.02 .2017 & 41 & 05.12 .2017 & 57 \\
21.01 .2017 & 79 & 15.02 .2017 & 44 & 07.12 .2017 & 62 \\
22.01 .2017 & 88 & 16.02 .2017 & 44 & 19.12 .2017 & 51 \\
23.01 .2017 & 117 & 17.02 .2017 & 49 & 20.12 .2017 & 45 \\
24.01 .2017 & 95 & 21.02 .2017 & 55 & 21.12 .2017 & 55 \\
25.01 .2017 & 48 & 22.02 .2017 & 39 & 22.12 .2017 & 49 \\
27.01 .2017 & 56 & 23.02 .2017 & 40 & 24.12 .2017 & 46 \\
28.01 .2017 & 59 & 22.08 .2017 & 58 & 26.12 .2017 & 44 \\
29.01 .2017 & 72 & 20.10 .2017 & 50 & 31.12 .2017 & 46 \\
\hline
\end{tabular}
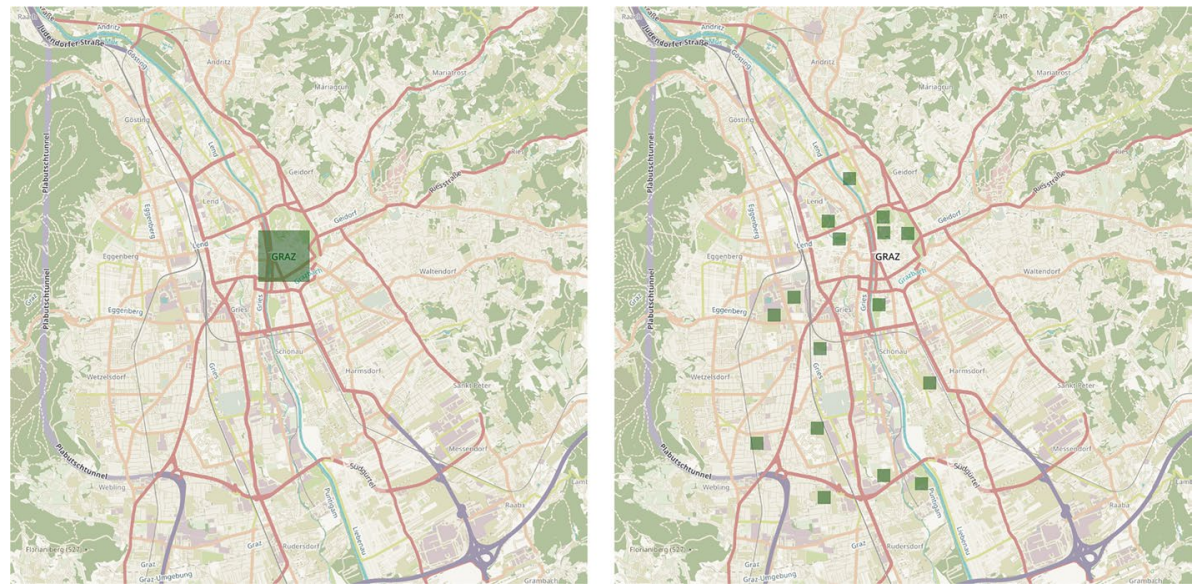

Fig. 3 Map of the investigated City of Graz. The dark green area is exactly the size of the simulated forest, i.e., $1 \mathrm{~km}^{2}$. Left: The area located in the middle of the city. Right: The same area distributed throughout the city

to $100 \mu \mathrm{g} / \mathrm{m}^{3}$ with a constant wind speed of $2 \mathrm{~m} / \mathrm{s}$. These sensitivity analyses are shown in Figs. 4 and 5 with error bars denoting the standard deviation. The point at which the leaves react to the wind is clearly visible, since the absorption decreases abruptly and then slowly recovers. The dependency of the absorption to the PM concentration is nearly linear, as expected. 


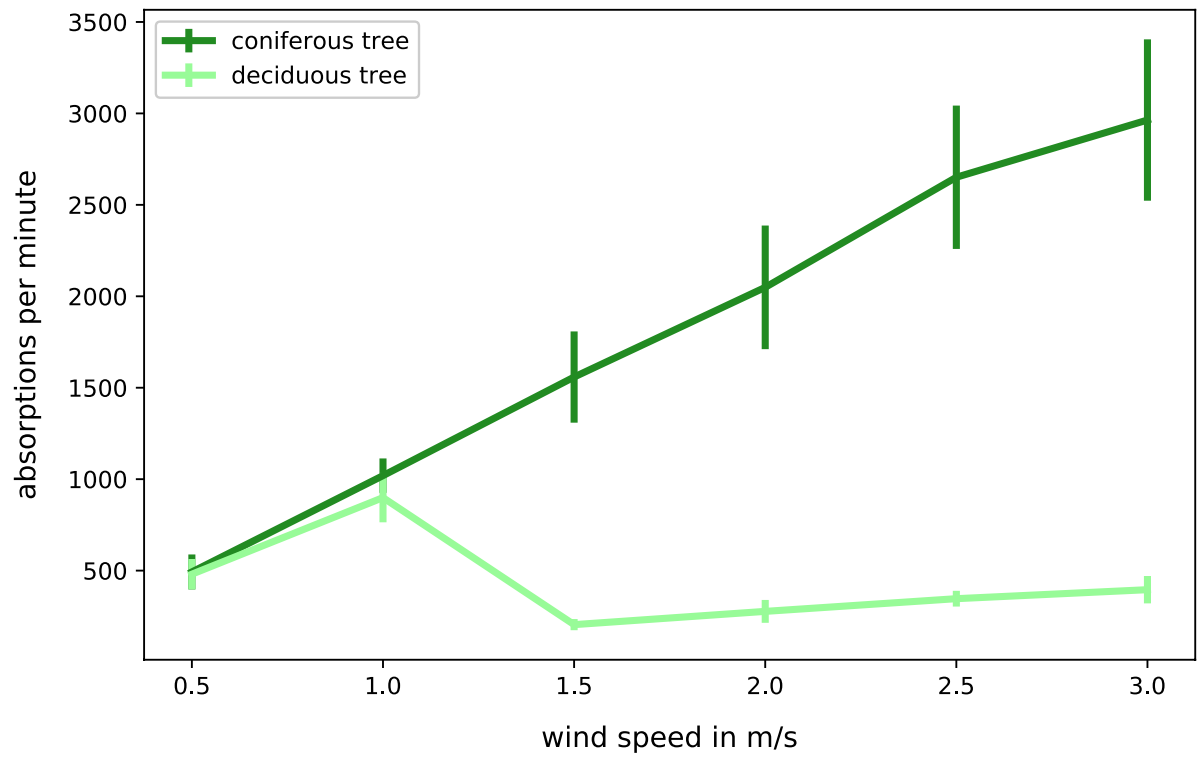

Fig. 4 Sensitivity of the simulation results to wind speed

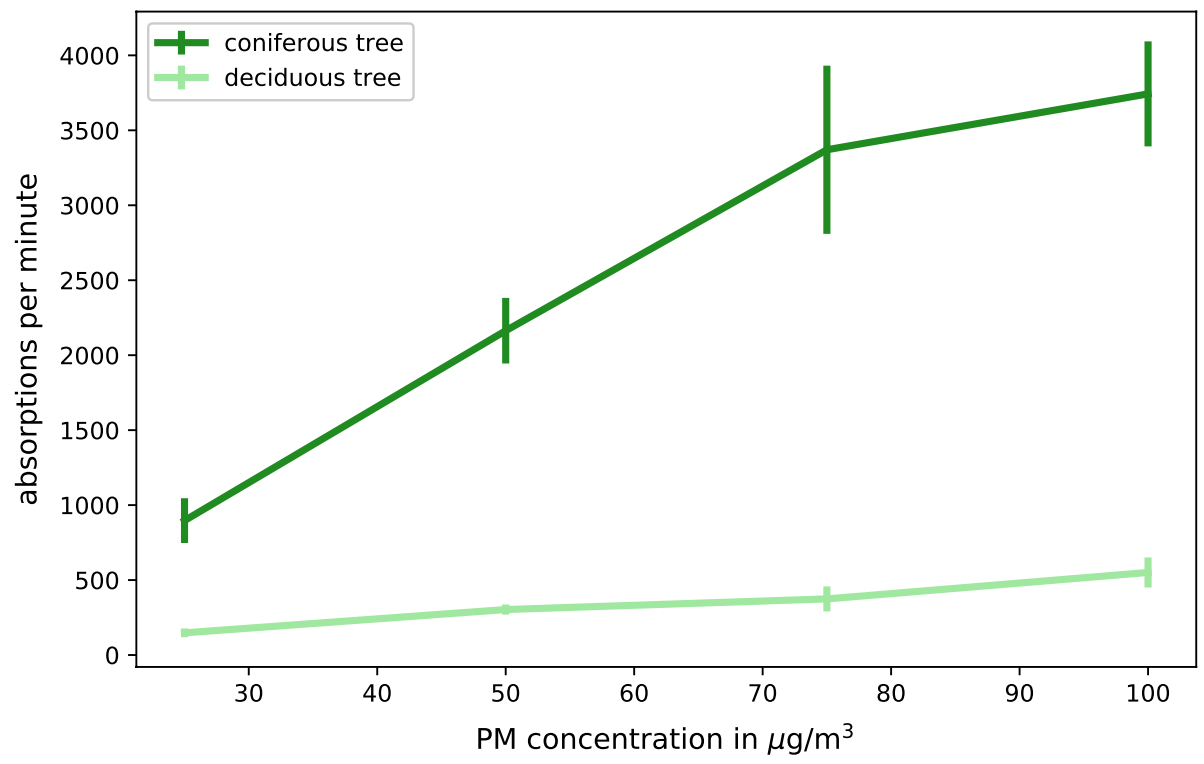

Fig. 5 Sensitivity of the simulation results to PM concentration

\section{Discussion}

Using a computer model, we were able to show the potential to absorb fine dust of different trees throughout the year. The species of trees is of great importance, especially since coniferous trees are also effective during the winter months, where the PM pollution is 
usually higher because of heating and weather effects. To calibrate the model to empirical data, we applied it to the situation of the City of Graz, an Austrian city with much PM pollution. We found that an area of $1 \mathrm{~km}^{2}$ of stone pines could be sufficient to reduce the fine dust pollution of Graz to an acceptable level.

However, there are some limitations that need to be mentioned. The model uses several simplifications which could lead to differences between simulation and reality. First of all, we assume a locally constant PM concentration. In reality, trees that are surrounded by other trees would be exposed to a lower concentration, thus limiting their absorption potential. Secondly, a planting density of $100 \%$ might be unrealistic, since there should be sufficient space between the individual trees, especially in an urban environment. This means that the actually needed green area might be bigger than in the simulation. Also the interaction between wind and trees is only approximated: In reality, the local wind speed is influenced by trees, so we overestimate the effect of the wind in the model. Another assumption that leads to an error is the assumption that absorbing $\mathrm{x} \%$ of the emitted pollution leads to an $\mathrm{x} \%$ reduction in PM concentration. While this is a good starting point, the reality is much more complex and the correct correlation would need further investigation. Additionally we are limited by the empirical data available, restricting us to a small number of tree species that can be investigated.

Several expansions could further improve the predictive power of the presented model. One could extend the simulation from a single leaf to several trees. In that way, spacial effects like a non-uniform wind speed and PM concentration would be included. Also the interaction between wind and leaves could be modeled in greater detail, using dynamic leaves. However, such expansions would significantly increase the computation time of the model and would require additional empirical data, which are currently not available.

Even though the presented model is simplified and thus may not lead to quantitatively correct results, it was still possible to show the potential of trees to absorb PM. In general, the model overestimates the absorption potential of trees; nevertheless, the qualitative results are accurate. Because of the change of pollution and wind throughout the year, coniferous trees are much better suited to absorb PM than deciduous trees and a large enough area would even be sufficient to solve the fine dust problem altogether in some urban areas. Since urban trees have many other benefits on local and global scales, it is definitely an idea worth further exploration.

Acknowledgements Open access funding provided by University of Graz.

Open Access This article is distributed under the terms of the Creative Commons Attribution 4.0 International License (http://creativecommons.org/licenses/by/4.0/), which permits unrestricted use, distribution, and reproduction in any medium, provided you give appropriate credit to the original author(s) and the source, provide a link to the Creative Commons license, and indicate if changes were made.

\section{References}

Amato, F., Querol, X., Johansson, C., Nagl, C., \& Alastuey, A. (2010). A review on the effectiveness of street sweeping, washing and dust suppressants as urban pm control methods. Science of the Total Environment, 408(16), 3070-3084.

Anderson, J. O., Thundiyil, J. G., \& Stolbach, A. (2012). Clearing the air: A review of the effects of particulate matter air pollution on human health. Journal of Medical Toxicology, 8(2), 166-175.

Baldasano, J. M., Gonçalves, M., Soret, A., \& Jiménez-Guerrero, P. (2010). Air pollution impacts of speed limitation measures in large cities: The need for improving traffic data in a metropolitan area. Atmospheric Environment, 44(25), 2997-3006.

Beckett, K. P., Freer-Smith, P., \& Taylor, G. (1998). Urban woodlands: Their role in reducing the effects of particulate pollution. Environmental Pollution, 99(3), 347-360. 
Belis, C., Karagulian, F., Larsen, B. R., \& Hopke, P. (2013). Critical review and meta-analysis of ambient particulate matter source apportionment using receptor models in europe. Atmospheric Environment, 69, 94-108.

Brenner, N. (2013). Theses on urbanization. Public Culture, 25(1(69)), 85-114.

Castells, M. (2010). Globalisation, networking, urbanisation: Reflections on the spatial dynamics of the information age. Urban Studies, 47(13), 2737-2745.

Clark, D. (2004). Urban world/global city. Abingdon: Routledge.

Contributors, O. (2012). Openstreetmap. URL www.openstreetmap.org.

Freer-Smith, P., El-Khatib, A., \& Taylor, G. (2004). Capture of particulate pollution by trees: A comparison of species typical of semi-arid areas (ficus nitida and eucalyptus globulus) with european and north american species. Water, Air, and Soil Pollution, 155(1-4), 173-187.

Harrison, R. M., \& Yin, J. (2000). Particulate matter in the atmosphere: Which particle properties are important for its effects on health? Science of the Total Environment, 249(1-3), 85-101.

Heiden, B., Henn, M., Hinterhofer, M., Schechtner, O., \& Zelle, K. (2008). Endbericht emissionskataster graz 2001, erstellt im auftrag dersteiermärkischen landesregierung. Forschungsgesellschaft fürVerbrennungskraftmaschinen und Thermodynamik mbH (FVT) undArbeitsgemeinschaft für Dokumentations-Graz: Informations-undPlanungssysteme.

Hoover, WG. (1986). Molecular dynamics. Lecture Notes in Physics, vol 258. Springer. https://doi.org/10.1007/ BFb0020009

Iio, A., Hikosaka, K., Anten, N. P., Nakagawa, Y., \& Ito, A. (2014). Global dependence of field-observed leaf area index in woody species on climate: A systematic review. Global Ecology and Biogeography, 23(3), 274-285.

Kappis, C., \& Endlicher, W. (2007). Studie zum wissenschaftlichen erkenntnisstand über das feinstaubfilterungspotential (qualitativ und quantitativ) von pflanzen. Unter Mitarbeit von Olga Gorbachevskaya, Christel Kappis, Rafael Valbuena, Hendrikje Schreiter, Anne Bergsträßer, Heidi Riedel und Babett Waschke Hg v Institut fürAgrar-und Stadtökologische Projekte an der Humboldt-Universität zu Berlin,(IASP) Berlin.

Karagulian, F., Belis, C. A., Dora, C. F. C., Prüss-Ustün, A. M., Bonjour, S., Adair-Rohani, H., et al. (2015). Contributions to cities' ambient particulate matter $(\mathrm{pm})$ : A systematic review of local source contributions at global level. Atmospheric Environment, 120, 475-483.

Li, T., Kheifets, S., Medellin, D., \& Raizen, M. G. (2010). Measurement of the instantaneous velocity of a brownian particle. Science, 328(5986), 1673-1675.

Lippmann, M., Frampton, M., Schwartz, J., Dockery, D., Schlesinger, R., Koutrakis, P., et al. (2003). The us environmental protection agency particulate matter health effects research centers program: A midcourse report of status, progress, and plans. Environmental Health Perspectives, 111(8), 1074.

McDonald, A., Bealey, W., Fowler, D., Dragosits, U., Skiba, U., Smith, R., et al. (2007). Quantifying the effect of urban tree planting on concentrations and depositions of pm10 in two uk conurbations. Atmospheric Environment, 41(38), 8455-8467.

Rai, P. K. (2016). Impacts of particulate matter pollution on plants: Implications for environmental biomonitoring. Ecotoxicology and Environmental Safety, 129, 120-136.

Seaton, A., Godden, D., MacNee, W., \& Donaldson, K. (1995). Particulate air pollution and acute health effects. The Lancet, 345(8943), 176-178.

Simon, D. (2007). Urbanisation and global environmental change: New intergenerational challenges. International Journal of Green Economics, 1(3-4), 299-306.

Steiermark, L. (2018). Online Luftgüte Daten Feinstaub. http://www.umwelt.steiermark.at/cms/beitrag/10470 928/3611708/, Accessed 11 Nov 2018.

Taebi, A., \& Droste, R. L. (2004). Pollution loads in urban runoff and sanitary wastewater. Science of the Total Environment, 327(1-3), 175-184.

Tarr, J. A. (1996). The search for the ultimate sink: urban pollution in historical perspective. Akron: The University of Akron Press.

Terzaghi, E., Wild, E., Zacchello, G., Cerabolini, B. E., Jones, K. C., \& Di Guardo, A. (2013). Forest filter effect: Role of leaves in capturing/releasing air particulate matter and its associated pahs. Atmospheric Environment, 74, 378-384.

Thurston, G. D., Ito, K., Mar, T., Christensen, W. F., Eatough, D. J., Henry, R. C., et al. (2005). Workgroup report: Workshop on source apportionment of particulate matter health effects-intercomparison of results and implications. Environmental Health Perspectives, 113(12), 1768.

Valavanidis, A., Fiotakis, K., \& Vlachogianni, T. (2008). Airborne particulate matter and human health: Toxicological assessment and importance of size and composition of particles for oxidative damage and carcinogenic mechanisms. Journal of Environmental Science and Health, Part C, 26(4), 339-362.

Wilensky, U. (1999). Netlogo. evanston, il: Center for connected learning and computer-based modeling. Evanston: Northwestern university. 
Zhang, X. Q. (2016). The trends, promises and challenges of urbanisation in the world. Habitat International, $54,241-252$.

Publisher's Note Springer Nature remains neutral with regard to jurisdictional claims in published maps and institutional affiliations. 